\title{
Kirurgisk behandling av epifrenisk oesophagusdivertikkel
}

\begin{abstract}
BAKGRUNN Epifreniske divertikler sitter i nedre $10 \mathrm{~cm}$ av oesophagus. Hovedsymptomer er dysfagi, regurgitasjon og smerter ved svelging av mat. Hovedhensikten med undersøkelsen var å evaluere avdelingens resultater av kirurgi ved denne sjeldne og plagsomme tilstanden.

MATERIALE OG METODE 11 pasienter (ni menn) ble i perioden 2002-12 operert for oesophagusdivertikkel med eksisjon ( $n=8$ ), myotomi av nedre oesophagussfinkter og Dors fundoplikasjon ( $n=2)$ eller samtlige prosedyrer $(n=1)$. To av disse ble overflyttet fra andre sykehus på grunn av komplikasjoner. Opplysninger om preoperative symptomer og postoperative komplikasjoner er hentet retrospektivt fra pasientjournaler. Ti pasienter som sa ja til etterundersøkelse besvarte et spørreskjema median 27,5 måneder (spredning 2-105 md.) etter operasjonen.
\end{abstract}

RESULTATER Ingen døde som følge av behandlingen. Tre pasienter fikk lekkasje etter divertikkeleksisjon, og to av disse måtte reopereres. Pasientene fikk betydelig symptomatisk bedring. Av de ni som hadde dysfagi preoperativt, var åtte kvitt dette ved etterundersøkelsen. Fire av sju med regurgitasjon og alle de fem med smerter ved svelging opplevde bedring postoperativt. Pasientene anga å være blitt helt bra $(n=5)$ eller bedre $(n=5)$ av operasjonen. Én pasient med reoperasjoner for lekkasje og øsofagomediastinal fistel, ville ikke latt seg operere igjen.

FORTOLKNING De fleste pasientene operert for epifrenisk oesophagusdivertikkel ved vår avdeling opplevde symptomatisk bedring etter kirurgisk behandling.

En epifrenisk oesophagusdivertikkel oppstår som følge av økt trykk i oesophagusveggen (pulsjonsdivertikkel). Divertikkelen sitter i distale $10 \mathrm{~cm}$ av oesophagus med herniering av mucosa og submucosa gjennom muscularis propria, vanligvis mot høyre i mediastinum (1). Divertiklene varierer i median størrelse fra $4 \mathrm{~cm}$ til $7 \mathrm{~cm}$ (spredning $1-14 \mathrm{~cm}$ ) i ulike materialer (1). Inntil $15 \%$ av pasientene har to eller flere divertikler. Motilitetsforstyrrelser i oesophagus, som uspesifikk dysmotilitet, diffus øsofageal spasme, akalasi og økt trykk i nedre oesophagussfinkter forekommer hos $75-100 \%$ av pasientene (1).

Oesophagusdivertikler påvises ved $<1 \%$ av øvre endoskopier og er antatt å forårsake $1-3 \%$ av alle tilfeller med dysfagi (2). Basert på radiologiske undersøker er prevalensen av epifreniske divertikler i den generelle befolkning beregnet til $0,015 \%$ i USA (3) og til $0,04-0,15 \%$ i Japan (4). I et mer selektert materiale fra Europa forelå epifrenisk divertikkel hos $2 \%$ av pasientene som ble undersøkt for svelgeforstyrrelser (5). Estimert årlig insidens i USA er ca. 1 per 500000 individer (6). At epifrenisk divertikkel er en sjelden tilstand, reflekteres også av små publiserte materialer, med 3-35 pasienter (1).

Det er rapportert at $37-63 \%$ av divertiklene gir symptomer (1). De vanligste er dysfagi, regurgitasjon, smerter ved svelging av mat og vekttap (1). Divertikler som gir milde eller ingen symptomer progredierer sjelden til symptomatisk sykdom (6). Ved større, symptomatiske divertikler er det økt risiko for komplikasjoner relatert til divertikkelen, for eksempel aspirasjonspneumoni. Konservativ behandling er rettet mot eventuell refluks. I enkelte tilfeller kan ballongdilatasjon forsøkes ved akalasi med stenose og økt trykk i nedre oesophagussfinkter (6).

Den opprinnelige kirurgiske behandlingen var venstresidig torakotomi med fridissekering og reseksjon av divertikkelen $(1,2)$. Ved samtidig akalasi eller påvist økt trykk i nedre oesophagussfinkter utføres i økende grad myotomi av oesophagus på motsatt side av divertikkelen samt en antirefluksoperasjon med vanligvis partiell fundoplikasjon for å motvirke sur og alkalisk gastroøsofageal refluks (1).

Operasjonene utføres i økende grad miniinvasivt og hyppigst med laparoskopisk tilgang (1). I et samlemateriale av 133 opererte pasienter fra perioden 1995-2008 (7) fant man at to døde under operasjonen. Postoperativ morbiditet ble rapportert hos $21 \%$, inkludert lekkasje fra oesophagus hos $15 \%$ av pasientene.

Hovedhensikten med denne studien var å evaluere resultatene etter kirurgi hos pasienter som ble operert for epifrenisk oesophagusdivertikkel i perioden 2002-12 ved Oslo universitetssykehus, Ullevål.

\section{Materiale og metode \\ Utvalg}

I perioden mai 2002 til september 2012 ble ni pasienter operert for epifrenisk oesopha-

\section{Tobias Hauge}

Det medisinske fakultet Universitetet i Oslo

\section{Egil Johnson}

egil.johnson@medisin.uio.no

Avdeling for gastro- og barnekirurgi

Oslo universitetssykehus, Ullevål

og

Institutt for klinisk medisin

Universitetet i Oslo

\section{Olav Sandstad}

Gastromedisinsk avdeling

Hans-Olaf Johannessen

Avdeling for gastro- og barnekirurgi

Erik Trondsen

Avdeling for gastro- og barnekirurgi

Oslo universitetssykehus, Ullevål

1

Engelsk oversettelse på www.tidsskriftet.no

\section{HOVEDBUDSKAP}

I perioden 2002-12 ble 11 pasienter som var blitt operert for epifrenisk oesophagusdivertikkel behandlet ved Oslo universitetssykehus, Ullevål

De fleste opplevde symptomatisk bedring

Alvorlige komplikasjoner ble registrert hos tre pasienter 
Tabell 1 Operasjonsmetode for epifrenisk oesophagusdivertikkel hos 11 pasienter operert i perioden 2002-12

\begin{tabular}{lc}
\hline Operasjon & $\begin{array}{c}\text { Antall } \\
\text { pasienter }\end{array}$ \\
Divertikkel eksidert & 9 \\
Via torakotomi & 6 \\
Via torakoskopi & 1 \\
$\begin{array}{l}\text { Via laparaskopi med samtidig } \\
\text { myotomi og fundoplikasjon }\end{array}$ & 1 \\
$\begin{array}{l}\text { Via torakotomi med oeso- } \\
\text { phagus- og ventrikkelreseksjon }\end{array}$ & 1 \\
$\begin{array}{l}\text { Divertikkel bevart } \\
\text { Via laparoskopi med myotomi } \\
\text { og fundoplikasjon }\end{array}$ & 2 \\
\hline
\end{tabular}

gusdivertikkel ved Oslo universitetssykehus, Ullevål. Pasientene ble identifisert ved å søke på diagnosen oesophagusdivertikkel (K22.5) i det elektroniske pasientjournalsystemet. I tillegg inkluderte vi to pasienter som ble overført til sykehuset etter operasjon ved andre sykehus i Ullevåls opptaksområde.

Pasienter som ble behandlet med stent eller avlastende gastrostomi ble ikke inkludert i materialet. Avdelingsoverlegen ved kirurgiske avdelinger i Ullevåls opptaksområde ble kontaktet telefonisk for å innhente

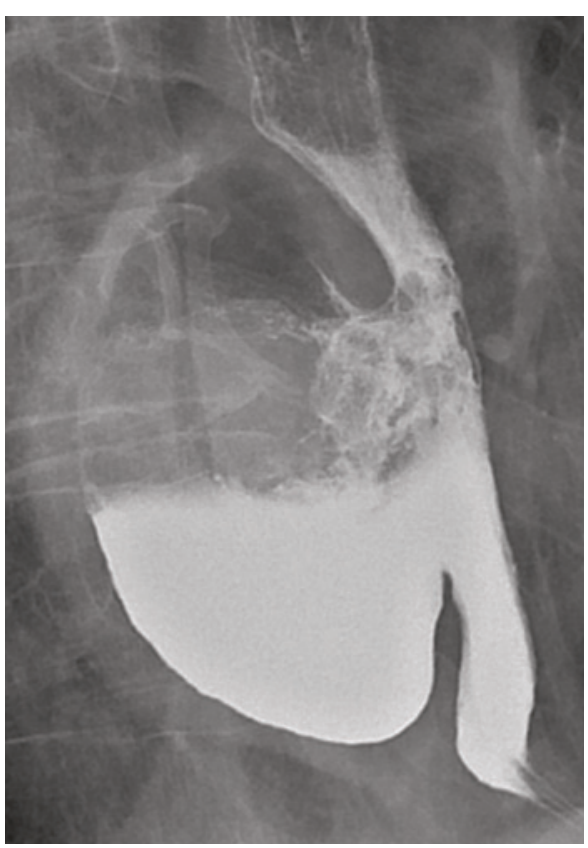

Figur 1 Stor, delvis kontrastfylt epifrenisk oesophagusdivertikkel vendt mot høyre i mediastinum opplysninger om hvorvidt andre pasienter var blitt operert.

\section{Variabler}

Opplysninger om pre- og postoperativt forløp ble innhentet retrospektivt fra journaler og registrert anonymisert $\mathrm{i}$ en database. $\mathrm{Vi}$ registrerte pasientens alder ved operasjonstidspunktet, preoperative symptomer (symptom til stede (ja/nei) samt hyppighet av regurgitasjon), symptomvarighet, preoperative undersøkelser, kirurgisk metode, postoperative komplikasjoner og liggetid.

Gjenlevende pasienter per desember 2012 $(\mathrm{n}=10)$ ble forespurt skriftlig om deltakelse $i$ en etterundersøkelse. Etterundersøkelsen inkluderte en poliklinisk kontroll, hvor 24 timers pH-måling ble tilbudt på indikasjon hos to pasienter. Pasientene fikk tilbud om kontroll med manometri, noe sju sa ja til.

De besvarte skriftlig spørsmål om symptomer, livskvalitet og deres vurdering av behandlingsresultatet. Spørsmål om symptomer gjaldt om symptomet var til stede eller ikke, for regurgitasjon om symptomet var til stede sjeldnere (daglig versus ukentlig) enn preoperativt. Data om symptomer og vurdering av behandlingsresultatet rapporteres her.

Svelgefunksjonen ble bedømt med modifisert Ogilvies skår, gradert fra 0 til 4 poeng (8). 0 poeng tilsier at pasienten klarer å innta all slags mat, 1 poeng noe fast føde, 2 poeng most mat og flytende, 3 poeng flytende mat, 4 poeng full stopp.

\section{Diagnostikk og behandling}

Preoperativt gjør vi CT-undersøkelse, røntgen oesophagus-ventrikkel-duodenum og/ eller gastroskopi for å bestemme divertikkelens størrelse, nivå og orientering i mediastinum og om det foreligger hiatushernie. Manometri kan avklare om pasienten trenger myotomi av nedre oesophagussfinkter og/eller en operasjon for å motvirke gastroøsofageal refluks.

Preoperative undersøkelser for opererte pasienter var gastroskopi $(n=9)$, computertomografi $(n=7)$, røntgen oesophagus-ventrikkel-duodenum $(\mathrm{n}=5)$, oesophagusmanometri $(\mathrm{n}=4)$ og 24-timers pH-måling i oesophagus $(n=2)$. To pasienter fikk diagnostisert akalasi.

Det ble benyttet ulike operasjonsmetoder (tab 1). Ved eksisjon av divertikkelen ble det fripreparert og eksidert, deretter ble m. propria adaptert over eksisjonsstedet. Dessuten ble det i noen pasienter utført Hellers myotomi (9) og Dors fundoplikasjon (9).

\section{Etiske overveielser}

Studien ble forelagt regional etisk komité i Helse Sør-Øst, som vurderte det som en ikke-fremleggelsespliktig kvalitetskontrollstudie. Den ble deretter godkjent av person- vernombudet ved Oslo universitetssykehus, Ullevål.

Det ble innhentet skriftlig samtykke til deltakelse i etterundersøkelsen. I tillegg ble det innhentet skriftlig samtykke til publisering av artikkelen fra samtlige opererte pasienter som var i live og fra pårørende til en avdød.

\section{Resultater \\ Utvalg}

Median alder var 60 år (spredning 53-77 år). Ni av 11 ble operert ved Oslo universitetssykehus, Ullevål. To pasienter ble overflyttet vår avdeling på grunn av komplikasjoner med lekkasje fra oesophagus. Ved forespørsel til avdelingsoverleger ble det ikke rapportert om flere pasienter operert for epifrenisk divertikkel i opptaksområdet for vårt sykehus $\mathrm{i}$ studieperioden. Symptomvarigheten hos pasientene før operasjon var median tre år (spredning 1-12 år).

\section{Kirurgi}

Divertikkel ble eksidert hos ni pasienter (tab 1). En av disse hadde akalasi og fikk i tillegg utført myotomi og fundoplikasjon. En pasient var noen år tidligere blitt operert med partiell divertikkelreseksjon. Operasjonen ble komplisert med lekkasje fra oesophagus. Pasienten fikk utført ukomplisert eksisjon av divertikkelen med åpen oesophagus- og ventrikkelreseksjon. Denne pasienten døde før etterundersøkelsen ble gjennomført. To pasienter med henholdsvis akalasi og dysmotilitet $\mathrm{i}$ distale oesophagus hadde små epifreniske divertikler som ikke ble eksidert. Hos disse pasientene ble det gjort myotomi og fundoplikasjon.

Postoperativ liggetid var median 16,5 dager (spredning 5-45 dager). For de åtte pasientene uten alvorlige komplikasjoner var det ti dager (5-16 dager). Største lengde av ekstirpert divertikkel (fig 1) var median $5 \mathrm{~cm}$ (spredning 3,5-9 cm). Halsen av divertikkelen mot oesophagus målte median $3 \mathrm{~cm}$ (spredning 1,5-5 cm).

\section{Komplikasjoner}

Ingen pasienter døde som følge av behandlingen. Tre pasienter fikk alvorlige komplikasjoner i form av lekkasje fra metallsuturraden $\mathrm{i}$ oesophagus. To av tre fikk lekkasje etter reseksjon av en solitær divertikkel. Hos disse ble det gjort torakotomi og debridement $\mathrm{i}$ thorax og midlertidig anlegging av heldekkende oesophagusstent.

En av disse pasientene fikk sekvele i form av fistel fra oesophagus til mediastinum. Fistelen ble eksidert et år senere. Den tredje pasienten fikk påvist mininimal kontrastlekkasje fra oesophagus. Pasienten ble holdt fastende og fikk antibiotika, og lekkasjen tilhelte, uten stenting, i løpet av en uke. 


\section{Symptomer og funn}

Etterundersøkelsen ble gjennomført median 27,5 måneder (spredning 2-105 md.) etter operasjonen. Postoperativt ble symptomet smerter ved svelging eliminert og antall pasienter med dysfagi og regurgitasjon ble betydelig redusert (tab 2). En pasient operert for akalasi med myotomi og fundoplikasjon hadde mild dysfagi (Ogilvies skår 1). Tre pasienter hadde fortsatt regurgitasjon, men redusert fra daglige til ukentlige episoder. Disse pasientene hadde preoperativt akalasi $(n=2)$ og lavt trykk i nedre oesophagussfinkter $(\mathrm{n}=1)$.

Postoperativ manometri ble utført hos sju pasienter median 17 måneder (spredning 7-94 md.) etter operasjonen. To av pasientene fikk også utført 24-timers pH-måling. Disse resultatene er sammenholdt med operasjonsmetode og preoperative funn (tab 3 ). Pasientene som ble operert med myotomi og fundoplikasjon hadde bedret motilitet i oesophagus etter operasjonen enn preoperativt. To pasienter hadde symptomgivende gastroøsofageal refluks ved etterundersøkelsen. De øvrige tre pasientene behandlet med eksisjon hadde normal manometri og ingen registrerte plager.

De ti etterundersøkte pasientene rapporterte at de var blitt helt bra $(n=5)$ eller bedre $(\mathrm{n}=5)$ av operasjonen. Én av pasientene med reoperasjoner for lekkasje og senere øsofagomediastinal fistel ville ikke latt seg operere igjen.

\section{Diskusjon}

De fleste pasientene i dette materialet rapporterte om symptomatisk bedring etter kirurgisk behandling av epifrenisk divertikkel, men tre fikk alvorlige komplikasjoner i form av lekkasje fra metallsuturraden i oesophagus.

I en oversikt fra 13 studier med 224 pasienter som fikk eksidert epifrenisk divertikkel, var det en letalitet på gjennomsnittlig $4 \%$ og lekkasje i lukningslinjen hos $12,5 \%$ av pasientene (6). Det var ingen letalitet $\mathrm{i}$ vårt materiale, men det var høy andel av lekkasje (3 av 11 pasienter). To av pasientene måtte behandles med en kombinasjon av kirurgi for sanering av infeksjon i pleurahulen og midlertidig stenting av oesophagus for å stoppe lekkasjen.

Alle etterundersøkte rapporterte full eller delvis tilbakegang av symptomene. Imidlertid hadde pasientene med akalasi $(\mathrm{n}=2)$ og lavt trykk i nedre oesophagussfinkter $(\mathrm{n}=1)$ fortsatt en del plager med dysfagi og/eller regurgitasjon. I sju studier der totalt 168 ble operert for solitær epifrenisk divertikkel, forelå utmerket eller godt symptomatisk resultat hos $72-93 \%$ (1).

Dysmotilitet i oesophagus og økt trykk i nedre oesophagussfinkter er ansett som de viktigste etiologiske faktorene ved utvikling

Tabell 2 Pre- og postoperative symptomer hos de ti pasientene som fylte ut spørreskjema ved etterunders $\emptyset$ kelsen. Pasientene anga om symptomet var til stede eller ikke. Dysfagi er her definert som en Ogilvies skåre på 1

\begin{tabular}{lcc}
\hline Symptom & Preoperativt & Postoperativt \\
Dysfagi & 9 & 1 \\
Regurgitasjon & 7 & 3 \\
Smerter ved svelging av mat & 5 & 0 \\
Gastroøsofageal refluks & Ukjent & 2 \\
\hline
\end{tabular}

av epifrenisk divertikkel $(1,6)$. I dette materialet ville pasienten som ved etterundersøkelsen hadde lavt trykk i nedre oesophagussfinkter og var plaget med betydelig regurgitasjon og lett refluks, sannsynligvis også vært tjent med en samtidig antirefluksprosedyre. Samtidig myotomi synes også å beskytte mot residiv av divertikkel (10). Og myotomi på motsatt side av ekstirpert divertikkel reduserer risikoen for lekkasje sammenliknet med eksisjon uten myotomi (6).

Til tross for et utmerket resultat etter divertikkeleksisjon hos sju pasienter med tilsynelatende normal nedre oesophagussfinkter i dette materialet, synes det rasjonelt også å gjøre myotomi hos slike pasienter. Selv om det ikke finnes prospektive randomiserte studier der man har sammenliknet åpen med laparoskopisk eksisjon av epifreniske divertikler, anbefaler flere forfattere $(1,6,7)$ at symptomgivende, mindre divertikler fjernes laparoskopisk. Laparoskopi er også velegnet for myotomi og fundoplikasjon.

Vi inkluderte kun pasienter som ble operert, og gjennomgangen sier således ikke noe om hvordan pasientenes symptomer hadde utviklet seg uten operasjon eller hvilke komplikasjoner man ville forvente hos dem som ikke blir operert. En litteraturgjennomgang viste imidlertid progrediering til behandlingstrengende sykdom hos 2,8\% av pasienter som er asymptomatiske eller kun har milde symptomer samt en risiko for progrediering på $92 \%$ for dem med symptomatisk sykdom (6).

\section{Konklusjon}

For de fleste av de 11 pasientene som ble operert for epifrenisk oesophagusdivertikkel og behandlet ved Oslo universitetssykehus, Ullevål, i en tiårsperiode var det symptomatisk bedring, men tre fikk alvorlige komplikasjoner i form av lekkasje fra oesophagus.

\section{Tobias Hauge (f. 1984)}

er turnuslege ved Drammen sykehus.

Forfatter har fylt ut ICMJE-skjemaet og oppgir ingen interessekonflikter.

\begin{tabular}{|c|c|c|c|}
\hline Pasient & Preoperativt & Operasjon & Postoperativt \\
\hline 1 & $\begin{array}{l}\text { Moderat dysmotilitet, } \\
\text { ingen refluks }\end{array}$ & Myotomi/fundoplikasjon & Bedret motilitet \\
\hline 2 & Akalasi & Myotomi/fundoplikasjon & $\begin{array}{l}\text { Normalisering av nedre } \\
\text { oesophagussphincter-trykk }\end{array}$ \\
\hline 3 & Ikke utført & Eksisjon & $\begin{array}{l}\text { Lavt trykk i nedre } \\
\text { oesophagussphincter } \\
\text { Liten refluks (9\%) }\end{array}$ \\
\hline 4 & $\begin{array}{l}\text { Normal manometri, } \\
\text { ingen refluks }\end{array}$ & Eksisjon & $\begin{array}{l}\text { Uspesifikk dysmotilitet, } \\
\text { betydelig refluks (28\%) }\end{array}$ \\
\hline 5 & Ikke utført & Eksisjon & Normal \\
\hline 6 & Ikke utført & Eksisjon & Normal \\
\hline 7 & Ikke utført & Eksisjon & Normal \\
\hline
\end{tabular}




\section{Egil Johnson (f. 1955)}

er spesialist i gastroenterologisk kirurgi, overlege og professor. Han er forskningsgruppeleder for oesophagus- og ventrikkelsykdommer. Forfatter har fylt ut ICMJE-skjemaet og oppgir ingen interessekonflikter.

\section{Olav Sandstad (f. 1957)}

er spesialist i medisinsk gastroenterologi og overlege. Han har interessefelt innen oesophagusmotorikk.

Forfatter har fylt ut ICMJE-skjemaet og oppgir ingen interessekonflikter.

\section{Hans-Olaf Johannessen (f. 1956)}

er spesialist i gastroenterologisk kirurgi og leder for Seksjon for $\varnothing v r e$ gastrokirurgi.

Forfatter har fylt ut ICMJE-skjemaet og oppgir ingen interessekonflikter.

\section{Erik Trondsen (f. 1947)}

er spesialist i gastroenterologisk kirurgi og overlege. Han har interesse for kirurgi ved benigne tilstander i oesophagus og ventrikkel. Forfatter har fylt ut ICMJE-skjemaet og oppgir ingen interessekonflikter.

\section{Litteratur}

1. Soares R, Herbella FA, Prachand VN et al. Epiphrenic diverticulum of the esophagus. From pathophysiology to treatment. J Gastrointest Surg 2010; 14: 2009-15

2. Thomas ML, Anthony AA, Fosh BG et al. Oesophageal diverticula. Br J Surg 2001; 88: 629-42.

3. Wheeler D. Diverticula of the foregut. Radiology 1947; 49: 476-82

4. Dobashi Y, Goseki N, Inutake Y et al. Giant epiphrenic diverticulum with achalasia occurring 20 years after Heller's operation. J Gastroenterol 1996; 31: 844-7.

5. Schima W, Schober E, Stacher G et al. Association of midoesophageal diverticula with oesophageal motor disorders. Videofluoroscopy and manometry. Acta Radiol 1997; 38: 108-14.

6. Zaninotto G, Portale G, Costantini M et al. Therapeutic strategies for epiphrenic diverticula: systematic review. World J Surg 2011; 35: 1447-53.

7. Hirano Y, Takeuchi H, Oyama T et al. Minimally invasive surgery for esophageal epiphrenic diverticulum: the results of 133 patients in 25 published series and our experience. Surg Today 2013; 43. $1-7$.

8. Ogilvie AL, Dronfield MW, Ferguson R et al. Palliative intubation of oesophagogastric neoplasms at fibreoptic endoscopy. Gut 1982; 23: 1060-7.

9. Patti MG, Molena D, Fisichella PM et al. Laparoscopic Heller myotomy and Dor fundoplication for achalasia: analysis of successes and failures. Arch Surg 2001; 136: 870-7

10. Plackett TP, Meghoo CA, Febinger DL. Recurrent epiphrenic diverticulum after transabdominal diverticulectomy: report of a case and review of the literature. Hawaii Med J 2009; 68: 13-5. 